\title{
Lack of Rybp in Mouse Embryonic Stem Cells Impairs Cardiac Differentiation
}

\author{
Olga Ujhelly, ${ }^{1}$ Viktoria Szabo, ${ }^{2}$ Gergo Kovacs, ${ }^{2}$ Flora Vajda, ${ }^{2}$ Sylvia Mallok, ${ }^{3}$ Janos Prorok, ${ }^{4}$ \\ Karoly Acsai, ${ }^{5}$ Zoltan Hegedus, ${ }^{6}$ Stefan Krebs, ${ }^{3}$ Andras Dinnyes, ${ }^{1,7}$ and Melinda Katalin Pirity ${ }^{2}$
}

Ring1 and Yy1 binding protein (Rybp) has been implicated in transcriptional regulation, apoptotic signaling and as a member of the polycomb repressive complex 1, it has an important function in regulating pluripotency and differentiation of embryonic stem cells (ESCs). Earlier, we had proved that Rybp plays an essential role in mouse embryonic and central nervous system development. This work identifies Rybp, as a critical regulator of heart development. Rybp is readily detectable in the developing mouse heart from day 8.5 of embryonic development. Prominent Rybp expression persists during all embryonic stages, and Rybp marks differentiated cell types of the heart. By utilizing rybp null ESCs in an in vitro cardiac differentiation assay, we found that rybp null ESCs do not form rhythmically beating cardiomyocytes (CMCs). Gene expression profiles revealed a downregulation of cardiac terminal and upregulation of germline-specific markers in the rybp null CMCs. Furthermore, transcriptome analysis uncovered a number of novel candidate target genes regulated by Rybp. Among these are several that are important in cardiac development and contractility such as Plagl1, Isl1, and Tnnt2. Importantly, forced expression of rybp in rybp-deficient ESCs by a lentiviral vector was able to rescue the mutant phenotype. Our data provide evidence for a previously unrecognized function of Rybp in heart development and point out the importance of germ cell lineage gene silencing during somatic differentiation.

\section{Introduction}

A COMPLEX NETWORK of transcription factors governs the spatiotemporal patterns of gene expression in the organs of the developing embryo proper. Transcription factors also have important roles in postnatal and adult life in maintaining the pattern of differentiated gene expression [1-3]. Ring 1 and Yy1 binding protein [Rybp, also known as Dedaf (Death Effector Domain-Associated Factor), UniGene Mm.321633; MGI:1929059] is a repressor protein that is also a member of the mammalian polycomb repressive complex 1 (PRC1) [4]. First, Rybp was described as a binding partner for the polycomb group protein (PcG) Ring1A (Ring1; ortholog of Drosophila dRing/Sce) and was also shown to associate with Ring1B (Ring2/Rnf2; ortholog of Drosophila dRing/Sce) and M33 (Pc1; ortholog of Drosophila Pc), components of the PRC1 multiprotein complex [5].

Our previous work showed that Rybp is selectively upregulated in distinct structures and cell types of the developing eye and the central nervous system (CNS), and it may also play a role in the development of more mature neurons $[6,7]$. We have also shown that rybp is essential for the development of the mouse embryo proper and that homozygous null mouse embryos cannot develop further implantation [embryonic day 5.5 (E5.5)]. Notably, in a subset of heterozygous animals and in $r y b p^{-/-} \leftrightarrow r y b p^{+/+}$chimeras, alterations in Rybp dosage induced striking neural tube defects (NTDs) [6,7]. These findings have demonstrated the integral role of Rybp at the early postimplantation and laterstage CNS development. Simultaneously, early embryonic lethality of the rybp homozygous null embryos were obstacles to the study of the precise role of Rybp at later developmental stages or the development of other organs.

In this study, the early lethal effect of Rybp deficiency was overcome by utilizing $r y b p^{-/-}$embryonic stem cells (ESCs) to model cardiac differentiation in the lack of Rybp. Our results showed that ESCs lacking functional Rybp are not able to form contractile cardiomyocytes (CMCs) and that Rybp is important for the proper expression of several key regulators of cardiac development. Recent data provide

\footnotetext{
${ }^{1}$ BioTalentum Ltd., Gödöllö, Hungary.

${ }^{2}$ Institute of Genetics, Biological Research Centre, Hungarian Academy of Sciences, Szeged, Hungary.

${ }^{3}$ Laboratory for Functional Genome Analysis (LAFUGA), Gene Center, LMU Munich, Munich, Germany.

${ }_{5}^{4}$ Department of Pharmacology and Pharmacotherapy, University of Szeged, Szeged, Hungary.

${ }^{5}$ MTA-SZTE Research Group of Cardiovascular Pharmacology, Szeged, Hungary.

${ }^{6}$ Institute of Biophysics, Biological Research Centre, Hungarian Academy of Sciences, Szeged, Hungary.

${ }^{7}$ Molecular Animal Biotechnology Laboratory, Szent Istvan University, Gödöllö, Hungary.
} 
the first evidence that Rybp is required for the formation of beating CMCs. This defines a novel role for Rybp in mammalian heart formation and has implications for the understanding of heart diseases.

\section{Materials and Methods}

\section{Experimental procedures}

All chemicals were purchased from Sigma-Aldrich and all the culture reagents were from Invitrogen Life Technologies, unless otherwise specified.

\section{Cell culture}

Mouse R1 [8] [hereafter mentioned as $r y b p^{+/+}$or wildtype (WT) ESCs] and rybp null [6] (hereafter mentioned as $r y b p^{-/-}$) ESCs were thawed on mitomycin C (MitC; SigmaAldrich) inactivated mouse embryonic fibroblast (MEF) layer and cultured on gelatin-coated tissue culture plates as described [9]. All cells were cultured at $37^{\circ} \mathrm{C}$ in a humidified atmosphere containing $5 \% \mathrm{CO}_{2}$. ESCs were cultured in ESC medium, consisting of Dulbecco's modified Eagle's medium GlutaMaxI, 15\% (v/v) ES cell qualified fetal calf serum (SLI Ltd.), $1 \%$ (v/v) nonessential amino acids, $1 \%$ (v/v) Pen/Strep, $100 \mu \mathrm{M}$ 2-mercaptoethanol, and 1,000 U/mL 1eukemia inhibitory factor (LIF, ESGRO; Chemicon/Millipore). Medium was changed daily on mouse ESC cultures and every 2 days during differentiation.

\section{Expression vectors}

To generate Rybp/Egfp expression constructs, we modified the original vector of Lois et al. to include a multiple cloning site and an IRES sequence upstream of the Egfp gene [10]. We cloned the Rybp cDNA to the multiple cloning site by the Xba1/Nhe1 digest. We also substituted the ubiquitin-C promoter by the promoter of the elongation factor- $1 \alpha(\mathrm{EF} 1 \alpha)$ gene.

\section{Production of lentiviruses}

All recombinant lentiviruses were produced by transient transfection of 293T cells, as described by Dull et al. [11]. The packaging constructs were obtained through Addgene (ref No: pMD2.G: 12259, pRSV-Rev: 12253, pMDLg/pRRE: 12251). The lentiviral particles were tested on $293 \mathrm{~T}$ cells.

\section{Transduction of ESCs}

Lentiviral particles were added to ESCs in expansion culture medium (MOI: 3-5) in the presence of $8 \mu \mathrm{g} / \mathrm{mL}$ polybrene and were centrifuged for $30 \mathrm{~min}$ on $1,000 \mathrm{~g}$ at $32^{\circ} \mathrm{C}$. After overnight incubation at $37^{\circ} \mathrm{C}$, the full medium was changed to fresh expansion medium. The cells were assayed 3 days after infection.

\section{Immunoblot analysis of ESCs}

Immunoblotting experiments of ESCs were carried out on $50 \mu \mathrm{g}$ protein from whole cell lysates fractionated by sodium dodecyl sulfate-polyacrylamide gel electrophoresis using secondary antibodies conjugated with horseradish peroxidase (HRP, AP132P; Millipore). The intensities of the reactive bands were detected by Bio-Rad Opti-4CN Substrate
Kit (170-8235). Anti-Rybp (anti-Dedaf 1:1,000, AB3637; Chemicon) was used for the detection of Rybp protein expression.

\section{Immunocytochemistry}

For immunofluorescence staining of the cells, cells were plated onto $0.1 \%$ gelatin-coated coverslips and fixed with 4\% paraformaldehyde (PFA) for $15 \mathrm{~min}$ at room temperature. Cells were permeabilized with $0.05 \%$ Triton-X-100/ phosphate-buffered saline (PBS) for $10 \mathrm{~min}$ at room temperature, followed by blocking in $1 \%$ bovine serum albumin for $1 \mathrm{~h}$ at room temperature. Cells were washed with PBS and incubated overnight with primary antibody at $4{ }^{\circ} \mathrm{C}$. Primary antibodies used for this study include Oct $3 / 4$ antibody (C-10, 1:100; Santa Cruz), anti-Rybp (anti-Dedaf 1:1,000, AB3637; Chemicon), and cardiac Troponin T antibody [Ms mAb Cardiac Troponin T (1C11) 1:2,000, ab8295; Abcam]. After washing thrice with PBS, cells were labeled with Alexa Fluor ${ }^{\circledR} 647$-conjugated secondary antibodies (for Oct3/4 antibody and for anti-Rybp; Invitrogen) and Alexa Fluor 488 Goat Anti-Mouse IgG $(\mathrm{H}+\mathrm{L})$ secondary antibody $(1: 2,000, \mathrm{~A} 11001$; Invitrogen) for $1 \mathrm{~h}$ at room temperature. Cells were then washed thrice with PBS and covered with DAPI mounting medium (VectaShield; Vector Laboratories). Imaging was performed with an Olympus $\mathrm{Ce}^{\circledR}{ }^{\circledR}$ Imaging microscope (Olympus Corporation) and with an Olympus LSM confocal microscope (Olympus Corporation). The captured images of immunocytochemistry (ICC) were semiquantified using Olympus FluoView software.

\section{Histology and immunohistochemistry}

Embryos and adult mouse testis were collected, washed thrice in PBS, fixed overnight with 4\% PFA, embedded in paraffin, and examined for general histological analysis. Serial sections were generated, and 4- $\mu \mathrm{m}$-thick sections were hematoxylin and eosin stained for morphology assessment and with anti-Rybp (anti-Dedaf 1:1,000, AB3637; Chemicon) for monitoring endogenous Rybp staining. The sections were analyzed and imaged by using a Zeiss AxioImager Z1 microscope (Carl Zeiss MicroImaging GmbH).

\section{mRNA expression analysis}

Total cellular RNA was isolated using the RNeasy Mini Kit (Qiagen) according to the manufacturer's instructions. The RNA prep was DNase treated (Promega), and transcribed by the Superscript II cDNA Synthesis Kit (Invitrogen, by Life Technologies), as per the manufacturer's instructions. Quantitative real-time polymerase chain reaction (RT-PCR) was performed in the SYBR Green JumpStart Taq ReadyMix (S4438) for the QPCR green master mix, in the Rotor-Gene Q real-time PCR machine (Qiagen). Gapdh was used as an internal control. Experiments were performed in triplicate and repeated at least twice. See primer sequences in Supplementary Table S1; Supplementary Data are available online at www.liebertpub.com/scd.

\section{In vitro cardiac differentiation}

For cardiac differentiation, embryoid bodies (EBs) were generated by the hanging-drop (HD) method as previously 
described [12]. For single-cell suspensions, the cells were dissociated from monolayer culture with $0.25 \%$ trypsinEDTA [day 0 (d0)]. The cells were counted, and 800 cells/ $20 \mu \mathrm{L}$ differentiation medium (ESC medium without LIF) were pipetted on the lid of a bacterial Petri-dish. The dish was filled with PBS to prevent the droplets from drying out. The cells were allowed to aggregate with the help of gravity by reversing the Petri-dish lid. On day 2, individual EBs were plated into a well of a 24 -well plate containing $0.1 \%$ gelatin-coated coverslips. Differentiation medium was changed every second day; the number of CMCs was continuously observed and recorded. The CMCs were further processed as required (eg, monitoring $\left[\mathrm{Ca}^{2+}\right]$ transient and cell contraction or mRNA expression analysis) or fixed on day 7 (d7), day 14 (d14), and day 21 (d21) for ICC.

\section{Quantification of beating activity of EBs}

Quantification of beating activity of EBs was performed as previously described $[13,14]$. In brief, the number of spontaneously beating clusters was recorded daily after plating EBs under a Nikon TMS inverted light microscope (Nikon Instruments, Inc.). The number of beating EBs was represented as the percentage of the total plated EBs. The cardiac beatings were further evaluated by grading of cardiac beating (area of cardiac beating and beating rate) as described earlier $[13,14]$. The results represent the mean \pm SEM of three independent experiments. Statistical analyses for a comparison of the percentage of the EB beating and the grading of EB beating between groups were conducted using a one-way ANOVA of SPSS Statistics version 18.0.

\section{Monitoring $\left[\mathrm{Ca}^{2+}\right]_{i}$ transient and cell contraction}

CMCs were loaded with $5 \mu \mathrm{M}$ Fluo-4 (Molecular Probes, Inc.), in DMSO $+20 \%$ pluronic acid F-127 (Sigma-Aldrich) in differentiation medium for $40 \mathrm{~min}$ in the dark at room temperature. Subsequently, myocytes were washed twice with normal Tyrode's solution and placed on the stage of an inverted fluorescent microscope (Eclipse TE2000; Nikon). The Tyrode's solution contained the following (in $\mathrm{mM}$ ): 144 $\mathrm{NaCl}, 0.4 \mathrm{NaH}_{2} \mathrm{PO}_{4}, 4 \mathrm{KCl}, 0.53 \mathrm{MgSO}_{4}, 1.8 \mathrm{CaCl}_{2}, 5.5$ glucose, and 5 HEPES, pH 7.4 with $\mathrm{NaOH}$. Fluo-4 was excited at $480 \mathrm{~nm}$; fluorescence emission was recorded at $535 \mathrm{~nm}$ by using appropriate filter sets (Chroma Technology). Optical signals were recorded by a photon counting photomultiplier module (H7828; Hamamatsu) and sampled at $1 \mathrm{kHz}$. Cell contraction was determined by a video edge detection system (VED-105; Crescent Electronics). Measurements were performed, and data were analyzed using the WinWCP software (V4.9.1. Whole Cell Electrophysiology Analysis Program, John Dempster, University of Strathclyde). All experiments were performed at room temperature.

\section{Global gene expression analysis by next-generation sequencing}

Cells from a $6 \mathrm{~cm}$ culture dish were harvested by resuspension in $500 \mu \mathrm{L}$ TRIzol (Invitrogen), and total RNA was extracted with the TRIzol method following the manufacturer's protocol. RNA was quality controlled by the nanodrop and bioanalyzer. High-quality RNA (RIN $>9$ and $260 / 230>2 ; 260 / 280>1.8)$ was converted to cDNA and
Illumina-compatible sequencing libraries using NuGEN Ovation and Encore NGS kits. Barcoded libraries were pooled and sequenced on an Illumina Genome Analyzer GAIIx in the single read mode with 80 nt read length. Reads were mapped to the mouse genome using TopHat [15]. Differentially expressed genes between wild-type and $r y b p^{-1-}$ ESCs were identified with DESeq and filtered for having a fold change $>1.5$ or $<-1.5$ and fdr $<0.05$. In the case of increasing gene expression, the fold change value was calculated by the expression ratio of the rybp ${ }^{-/-}$and the wild-type samples; however, when the gene expression showed a decreasing tendency, the negative reciprocal of this quotient was used for the fold change calculation. Significant genes were uploaded to the Ingenuity Pathway Analysis (IPA) (www.ingenuity.com) platform, where functional enrichment studies were executed. The extent of overrepresentation was quantified by the Benjamini-Hochberg corrected significance value that was calculated by using the Fisher's Exact test. Gene annotation information was either derived from the knowledge base of IPA or collected from the Ensembl database using the BioMart tool.

\section{Results}

\section{Rybp is abundantly expressed in the developing mouse heart}

To gain further support for the presence of Rybp in different organs besides CNS, we examined the distribution of rybp mRNAs by Northern blotting analysis using total RNA isolated from multiple mouse tissues. Our results demonstrated that the major $4.7 \mathrm{~kb}$ isoform of rybp is highly expressed in the heart and also in other mouse tissues (kidney, liver, skin, small intestine, thymus) (Fig. 1A). To confirm that Rybp is also present at the protein level in the developing mouse heart, we examined its expression pattern by utilizing anti-Rybp (anti-Dedaf) antibody on embryonic sections. Rybp was shown to be readily detectable in the developing heart from day 8.5 of embryonic development (E8.5) (Fig. 1B). Prominent Rybp expression persisted during all embryonic stages examined and Rybp marked differentiated cell types of the heart, suggesting its involvement in heart development and differentiation.

\section{rybp null ESCs do not form rhythmically beating CMCs}

Abundant expression of Rybp in the heart prompted us to investigate the role of Rybp in the regulation of cardiac lineage commitment. To investigate the function of Rybp during cardiac differentiation, we utilized rybp null $\left(r y b p^{-/-}\right)$ ESCs lacking functional Rybp protein product [6] (Fig. 1C). $R y b p^{-1-}$ ESCs are viable and display typical ES cell morphology when grown on an MEF monolayer, forming round and oval-shaped compact colonies, indistinguishable from those that formed by the wild-type cells [6] (Fig. 1D). We used the classic HD method to generate EBs as a common intermediate during the in vitro differentiation of pluripotent stem cells into CMCs (Fig. 2A and Materials and Methods). Differentiation in brief, to induce ESC differentiation LIF, was withdrawn from the culture medium and cells were kept as HDs $(800$ cells $/ 20 \mu \mathrm{L})$ to form EBs. Two days later, EBs were transferred into a suspension culture system. At d4 of 
A

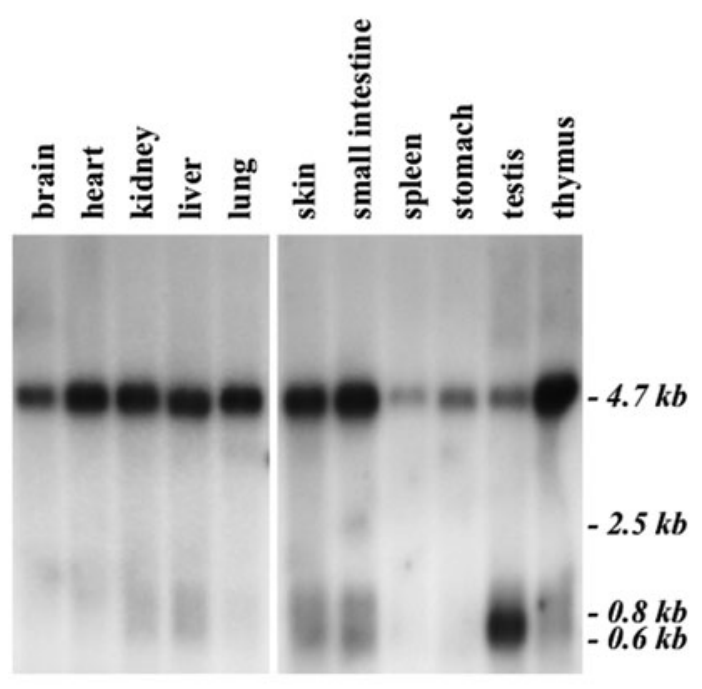

B

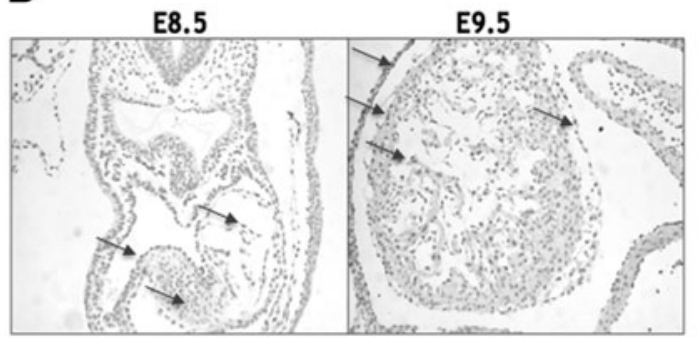

C
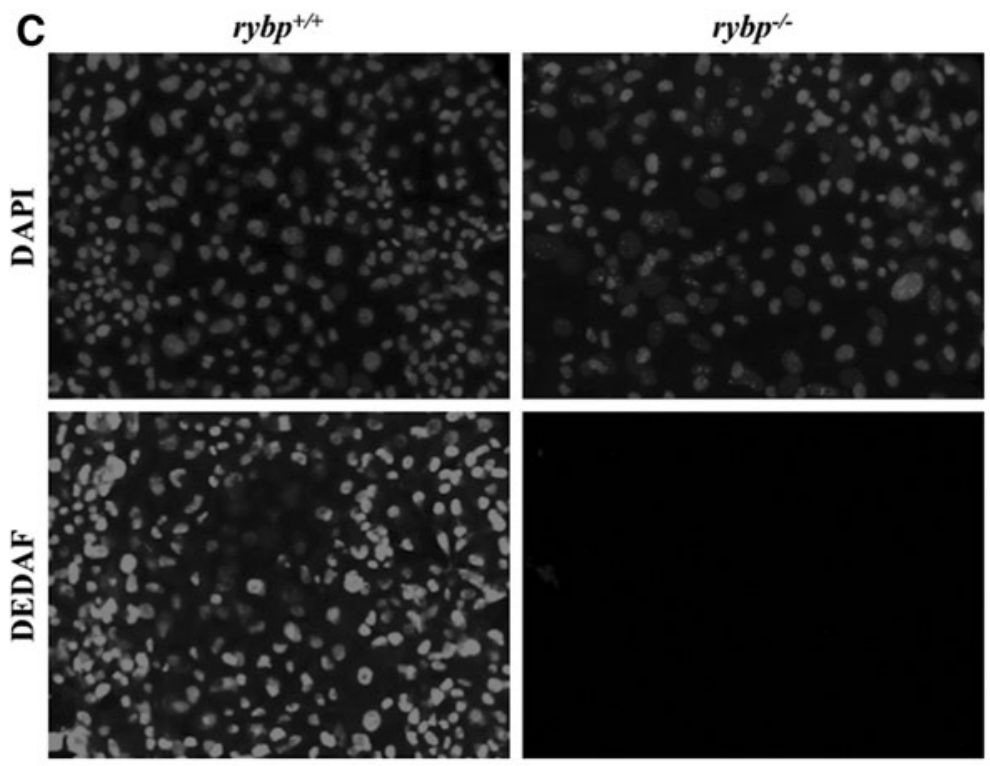

D

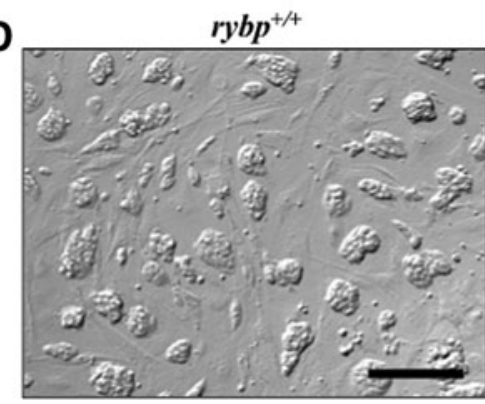

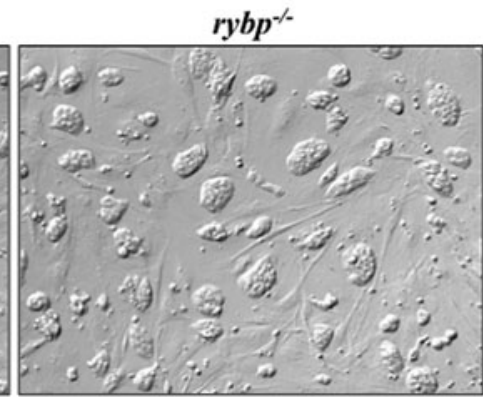

FIG. 1. Rybp is abundantly expressed in the embryonic and adult mouse heart. (A) Northern blot analysis with rybpspecific probe identifies a $4.7 \mathrm{~kb}$ major transcript in various mouse tissues and a $0.6 \mathrm{~kb}$ mRNA transcript expressed abundantly only in testis. Several rybp isoforms at lower-molecular-weight range $(0.6-0.8 \mathrm{~kb})$ are also visible in multiple tissues (kidney, liver, skin, small intestine thymus). The smallest molecular weight $0.6 \mathrm{~kb}$ isoform is not present in the heart and the brain. A $2.5 \mathrm{~kb}$ transcript is only present in the small intestine. (B) Representative examples of immunohistochemistry performed with an anti-Rybp (anti-Dedaf; Chemicon) antibody (dark gray staining, arrows) on counterstained (light gray) sections from early postimplantation developmental stages (E8.5; E9.5) in normal mouse embryos showing Rybp expression in the heart. (C) Immunostaining of wild-type $\left(r y b p^{+/+}\right)$and $r y b p^{-i-}$ ESCs for Rybp. ESCs were fixed and immunostained with anti-Dedaf antibody (light gray) and DAPI (dark gray). Rybp null ESCs are not expressing Rybp. Magnification: $20 \times$. (D) Bright field images of undifferentiated wild-type and rybp-null ESC colonies. Rybp null ESCs are viable and display a typical ES cell morphology. Colonies are composed of small cells attached to each other with a high N/C (nucleoplasm/cytoplasm) ratio where a single cytoplasm is not detectable. Based on gross morphology, the rybp ${ }^{-/-} \mathrm{ESCs}$ show the typical mouse ES cell morphology. Cells were grown on the MEF layer. Scale bar $=100 \mu \mathrm{m}$. ESCs, embryonic stem cells; MEF, mouse embryonic fibroblast; Rybp, Ring1 and Yy1 binding protein.

differentiation, the EBs were placed onto gelatin-coated coverslips, one of each of the coverslips, and they were grown for another 10 days. We subjected undifferentiated (d0) and differentiated ( $\mathrm{d} 8$ and $\mathrm{d} 14$ ) cell samples to analysis. Both WT and $r y b p^{-1-}$ ESCs formed EBs and attached to the gelatin-coated surface of the dishes, and WT ESCs formed rhythmically beating CMCs in 6-14 days (Fig. 2B). We found that although EBs could be derived from the rybp null ESCs no beating colonies were observed from the mutant cells (Fig. 2B). Out of 400 WT EBs, 93\% formed beating $\mathrm{CMCs}$ when they were allowed to attach on gelatin-coated surfaces by the 14th day of differentiation while none was beating from the $r y b p^{-/-}$genotype. Studies using Fluo-4 $\mathrm{Ca}^{2+}$-sensitive dye confirmed that $r y b p^{-1-} \mathrm{CMCs}$ cannot produce intracellular $\left[\mathrm{Ca}^{2+}\right]$ transient, indicating that the defective $\mathrm{Ca}$ handling may contribute to the loss of cell shortening (Fig. 2C). Analysis of gross morphology of derived $\mathrm{CMCs}$ showed decreased colony size and less cell content in the rybp null ESCs than the wild type at each examined timepoints of in vitro cardiac differentiation (Fig. 2D). This suggested that in vitro cardiac differentiation was affected by the absence of functional rybp.

\section{Ascorbic acid fails to induce contractility of the rybp ${ }^{-/-}$CMCs}

Ascorbic acid (ASC) is a known inducer of cardiac differentiation and robustly enhances cardiac differentiation of even cell lines without spontaneous cardiogenic potential. Therefore, we have added ASC supplement in the differentiation medium of the rybp null mutant cells to test whether their cardiogenic potential can be further increased in the 
A Hanging

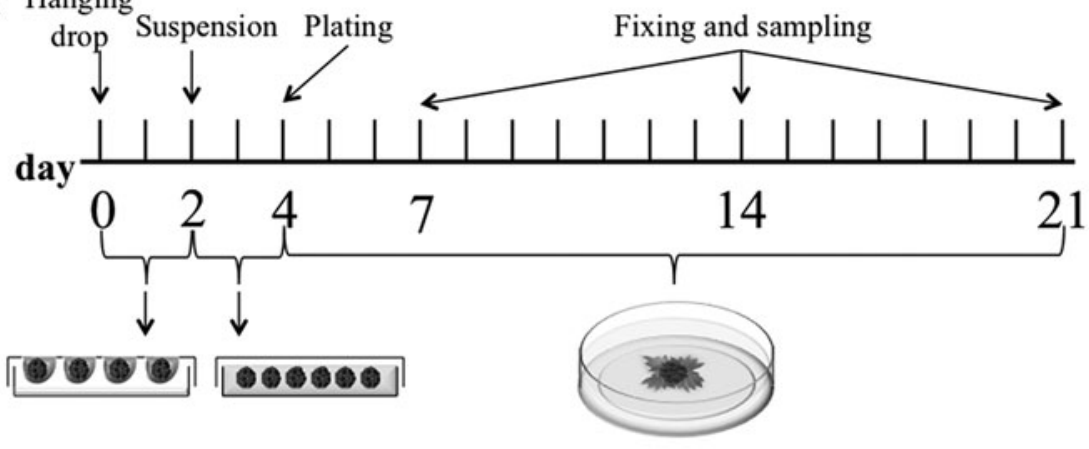

B
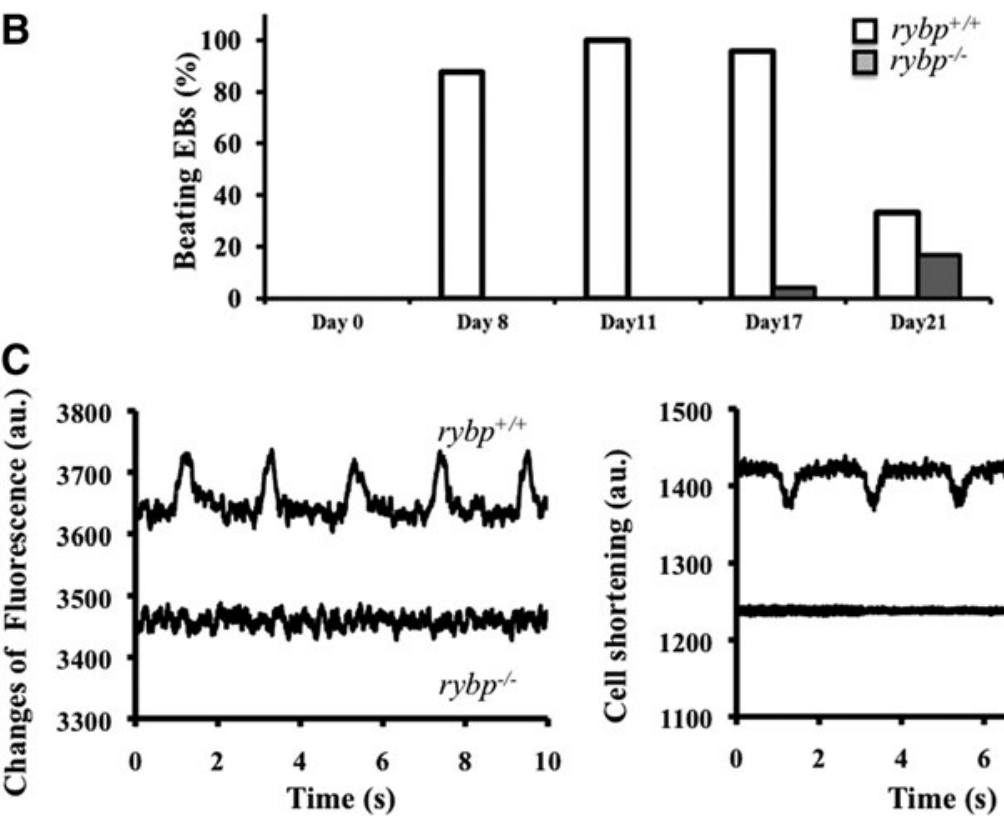

D

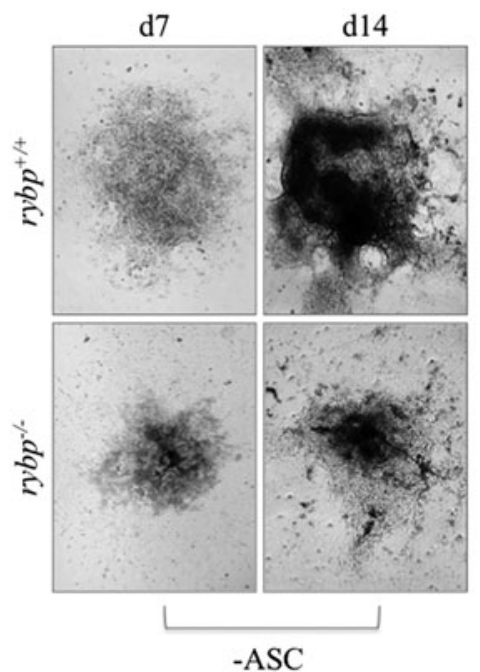

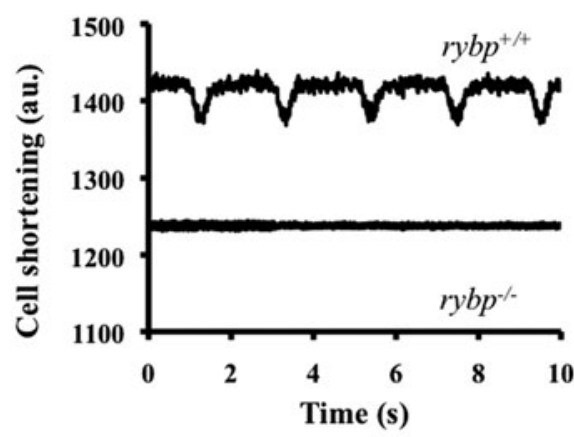

d7

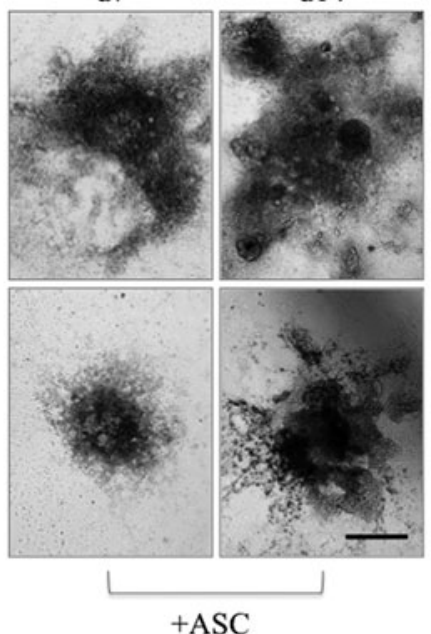

FIG. 2. The $r y b p^{+/+}$and $r y b p^{-/-}$ ESC lines show differences in morphology of differentiated CMC colonies and in contractile activity. (A) Schematic representation of in vitro cardiac differentiation. $\mathrm{CMCs}$ were differentiated in vitro from ESCs by using the hanging-drop method. CMC colonies were grown for 21 days and sampled at different time points (eg, day 0, 7, 14 and 21) as further required. (B) Quantitative analysis of beating $\mathrm{CMC}$ colonies derived from $r y b p^{+/+}$and $r y b p^{-/-}$ESCs. Vertical axis indicates the percentage of beating colonies; horizontal axis shows the days of observation (day 8, 11, 17 and 21). Day 0 corresponds to the undifferentiated ES cell stage (no beating). Ninety-three percent of $r y b p^{+++}$CMC colonies were beating from day 8 , and rybp ${ }^{-\prime-} \mathrm{CMC}$ colonies showed weak contractile activity only at day $17(\sim 5 \%)$ and day 21 ( 20\%). (C) Original recordings from 12 days old beating $r y b p^{+/+}$and nonbeating $r y b p^{-1-}$ CMCs derived from mouse ESCs. Left panel shows the changes of intracellular $\mathrm{Ca}^{2+}$ concentration as a $\mathrm{Ca}^{2+}$-dependent fluorescent signal (F535 nm). Right panel shows the corresponding cell shortening. (D) Comparison of $r y b p^{+/+}$and $r y b p^{-1-}$ CMC morphology with and without ASC treatment at day 7 and 14 shows prominent differences. The CMCs derived from WT $\left(r y b p^{+/+}\right)$ESC line had grown in multiple layers, while the mutant $\left(r y b p^{-/-}\right)$colonies were scattered and thin. CMCs derived from both ESC lines formed larger and more developed colonies with ASC induction. ASC, ascorbic acid; CMC, cardiomyocyte; WT, wild type. presence of ASC. We found that ASC was not able to induce the contractility of the $r y b p^{-1-}$ derivatives any further. However, as a result of the ASC treatment, cell populations from both genotypes grew and formed bigger colonies with visibly more cell layers than without ASC (Fig. 2D). This suggested that the rybp null mutant cells cannot form beating CMCs either spontaneously or after induction by ASC.
Lack of Rybp affects Is/1, Tnnt2, and Tbx3 expression in CMCs

To gain insights into underlying molecular events, we have measured the expression of lineage-specific markers in the $r y b p^{-1-}$ ESCs and compared them with the WT cells. We have also measured marker gene expression during the 
time course of cardiac differentiation $(\mathrm{d} 2,4,8,10,14)$ in both genotypes. Analysis revealed no significant changes in gene expression level of the key pluripotency genes (Rex1, Oct4, Nanog) (Fig. 3) and pan-mesodermal markers (T/Bra, Gsc) (Fig. 3). The expression of all examined pluripotency markers was progressively downregulated in both cell populations by differentiation. This suggested that silencing of pluripotency gene expression was properly executed in the $r y b p^{-1-}$ cells as well. Importantly, further gene expression analysis revealed downregulation of the terminal cardiogenic marker cardiac troponinT (Tnnt2) in the mutants, suggesting that cardiac lineage commitment was impaired in
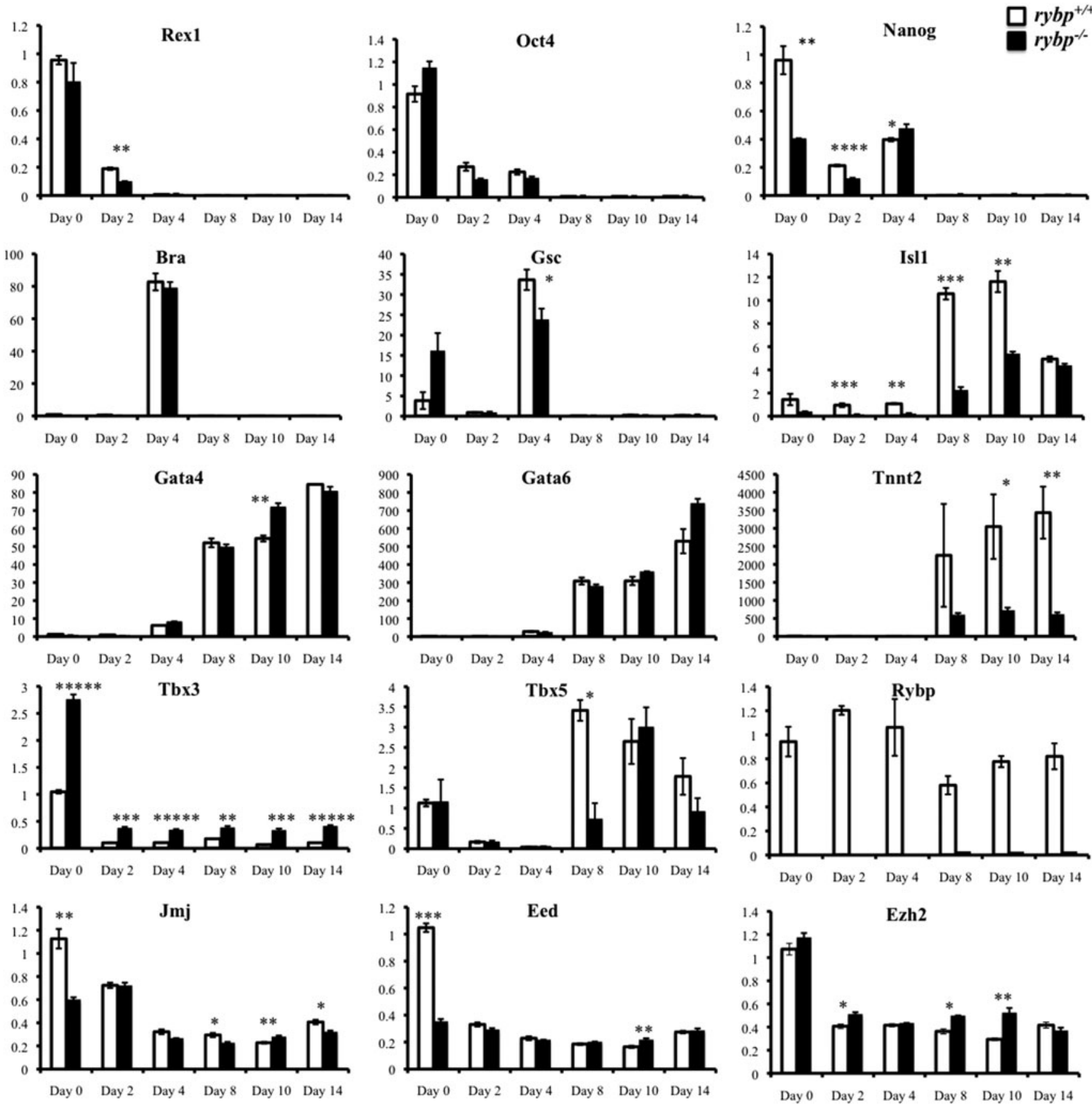

FIG. 3. $r y b p$-deficient ESCs are impaired in cardiac differentiation and expression of pluripotency (Rex1, Oct4, Nanog), early mesodermal (Bra, Gsc), early cardiac (Is11, Gata4, Gata6), T-box (Tbx3, Tbx5), and PcG (Jmj, Eed, Ezh2) genes during in vitro cardiac differentiation. For quantitative real-time polymerase chain reaction (RT-PCR) analyses, RNA was extracted, reverse transcribed from differentiated cardiac cells generated from WT and rybp ${ }^{-1-}$ ESCs at day $0,2,4,8,10$, and 14 of differentiation, and analyzed for expression of marker genes. Gapdh transcripts were amplified as an internal control. The expressions of the indicated markers were relative gene expression changes and were normalized to Gapdh expression. Quantitative RT-PCR was performed with the primers listed in Supplementary Table S1. Values and means: $\pm \mathrm{SD} * P<0.05$; $* * P<0.01$; $* * * P<0.001$; **** $P<0.0001$; ***** $P<0.00001(n=5)$ Statistical method: $t$-test type 3 . $\mathrm{PcG}$, polycomb group protein. 
the $r y b p^{-/-}$cells. By examining the earlier steps of cardiac lineage commitment (Isl1, Gata4, Gata6 expression), we found no significant differences in the expression of Gata4 and Gata6 expression (Fig. 3) while Isl1 expression was impaired in the mutants (near $6 \times$ more in the WT cells) (Fig. $3)$. Isl1 is a homeobox transcription factor and an essential regulator of cardiac progenitor differentiation. Rybp may function as a member of PRC1 [4,16] and regulate the expression of homeobox-type transcription factors during heart development. Therefore, we have also examined whether the expressions of the T-box (homeobox-type) cardiac transcription factors (Tbx3, Tbx5) were changed. CMCs lacking rybp showed more than a 2-fold increase in Tbx3 expression compared with WT (Fig. 3); however, the level of Tbx5 did not change significantly. Together, the data suggested that while expression of pluripotency genes was commonly downregulated, differentiation-driven activation of some cardiac transcription factors, such as the homeoboxtype Is11 and Tbx3, is different between cells expressing Rybp and those lacking Rybp.

Polycomb-repressive complex 2 (PRC2) regulates the balance between self-renewal and differentiation of ESCs. Therefore, we have examined whether loss of rybp results in the altered expression of PRC2 members. Our data showed no significant alterations in $\mathrm{PcG}$ expression levels, including Ezh2, Eed, and also PCR2 regulator Jmj. This suggests that lack of rybp (Fig. 3) has no significant influence on the expression level of the PRC2 members. These results also showed that Rybp is necessary for the proper execution of CMC differentiation.

\section{Transcriptome analysis reveals a spectrum of genes with altered expression profile in the rybp null ESCs and CMCs}

To examine possible gene expression alterations in a broader spectrum and to examine which signaling pathways are influenced by the lack of rybp, we have performed a quantitative comparative transcriptome analysis with the Illumina genome analyzer. We have compared the gene expression profile of the undifferentiated $r y b p^{-/-}$and WT ESCs (d0). We also performed analysis on differentiated ESCs (d8, d14). D8 represents an earlier time point and d14 corresponds to a later time point of in vitro cardiac differentiation and lineage commitment. Using the filtering criteria of a two-or-greater fold change in expression and a false discovery rate of less than $1 \%, 53$ out of more than 20747 transcripts were differentially expressed at the undifferentiated stage (d0) (Table 1). At the differentiated stage $3 \%, 716$ out of more than 23045 transcripts were at $\mathrm{d} 8$ (early stage) (Table 1) and $3.5 \%, 768$ out of more than

Table 1. Gene Expression Changes in $R Y B P^{-/-}$Cells

\begin{tabular}{lccc}
\hline & $\begin{array}{c}\text { Significant } \\
\text { increase }\end{array}$ & $\begin{array}{c}\text { Significant } \\
\text { decrease }\end{array}$ & $\begin{array}{c}\text { Genes } \\
\text { detected }\end{array}$ \\
\hline d0 & 24 & 29 & 20747 \\
d8 & 392 & 324 & 23045 \\
d14 & 477 & 291 & 21982 \\
\hline
\end{tabular}

d, day.
21982 transcripts were at d14 (late stage) (Table 1). Under these conditions, there were 25 transcripts with increased expression in the rybp null ESCs (d0), while 30 transcripts showed decreased expression (Supplementary Tables S2 and S3). There were 393 transcripts with increased expression in the rybp null ESCs at d8, while 325 transcripts showed decreased expression (Supplementary Tables S2 and S3). At d14 of cardiac differentiation, 478 transcripts showed increased expression and 292 showed decreased expression (Supplementary Tables S2 and S3). To identify the biological processes in which genes transcriptionally affected in $r y b p^{-/-}$ESCs are involved, we performed gene function enrichment analysis using the IPA knowledge base. At the undifferentiated stage (d0), ESCs displayed the most striking effect that was recorded in genes that were critical for germ development. The transcriptome analysis revealed that genes critical for germ development were de-repressed in comparison to the WT ESCs (eg, Tex11, Tex13, Piwil2, Dazl, Rnf17) (Supplementary Tables S2 and S3). These genes are involved in the early stage of spermatogenesis and are also expressed in primordial germ cells. Immunostaining of adult testis confirmed that Rybp was localized in spermatogonia and weak staining of spermatocytes, but it was not visible in spermatids or Sertoli or Leydig cells (Supplementary Fig. S1). The transcriptome analysis of $\mathrm{d} 8$ and d14 differentiated cells showed that other genes, involved in the later stage of sperm development, are also de-repressed (eg, Ddx4, Mael, Syce1, Sycp3). The IPA analysis revealed a significant enrichment in different Gene Ontology Biological Process categories, such as apoptosis (d8: Supplementary Table S4; d14 Supplementary Table S5) in which $r y b p$ is already known to be involved $[17,18]$. This observation suggests that $r y b p$ deficiency has an effect on the transcriptome in ESCs, which is consistent with the data obtained.

\section{Altered expression level of genes important for cardiovascular system development and function in the rybp-deficient CMCs}

To better understand the precise role of rybp in heart development, we conducted functional enrichment assay using IPA. The IPA analyses revealed that several cardiovascular-related gene sets can be found among most overrepresented physiological functions in the rybp-deficient samples during cardiac differentiation (d8: Fig. 4A, day 14: Fig. 4B). Genes of this functional category with significantly different expression in WT and $r y b p^{-/-}$ESCs are listed in Supplementary Table S6 (d8) and Supplementary Table S7 (d14). Given these data, which provided additional evidence that absence of rybp has an effect on the transcriptome in ESCs and CMCs, we further analyzed the data obtained by DNA-seq and searched for genes expressed in the heart and for genes already known to have a cardiac phenotype in mouse models. One of the most downregulated genes expressed during cardiac differentiation is Plagl1 (d0: $\mathrm{FC}=$ $-13.86, \operatorname{padj}=2.3 \times 10^{-5} ; \mathrm{d} 8: \mathrm{FC}=-76.79, \operatorname{padj}=3.44 \times$ $10^{-77} ; \mathrm{d} 14: \mathrm{FC}=-92.91$, padj $=2.68 \times 10^{-79}$; Supplementary Table S3). Plagl1 is an essential factor for cardiac morphogenesis and is highly expressed in mouse hearts from E8.5 to adulthood in a chamber-restricted pattern. In the rybp null ESCs, Plagl1 is nearly absent at all timepoints of 

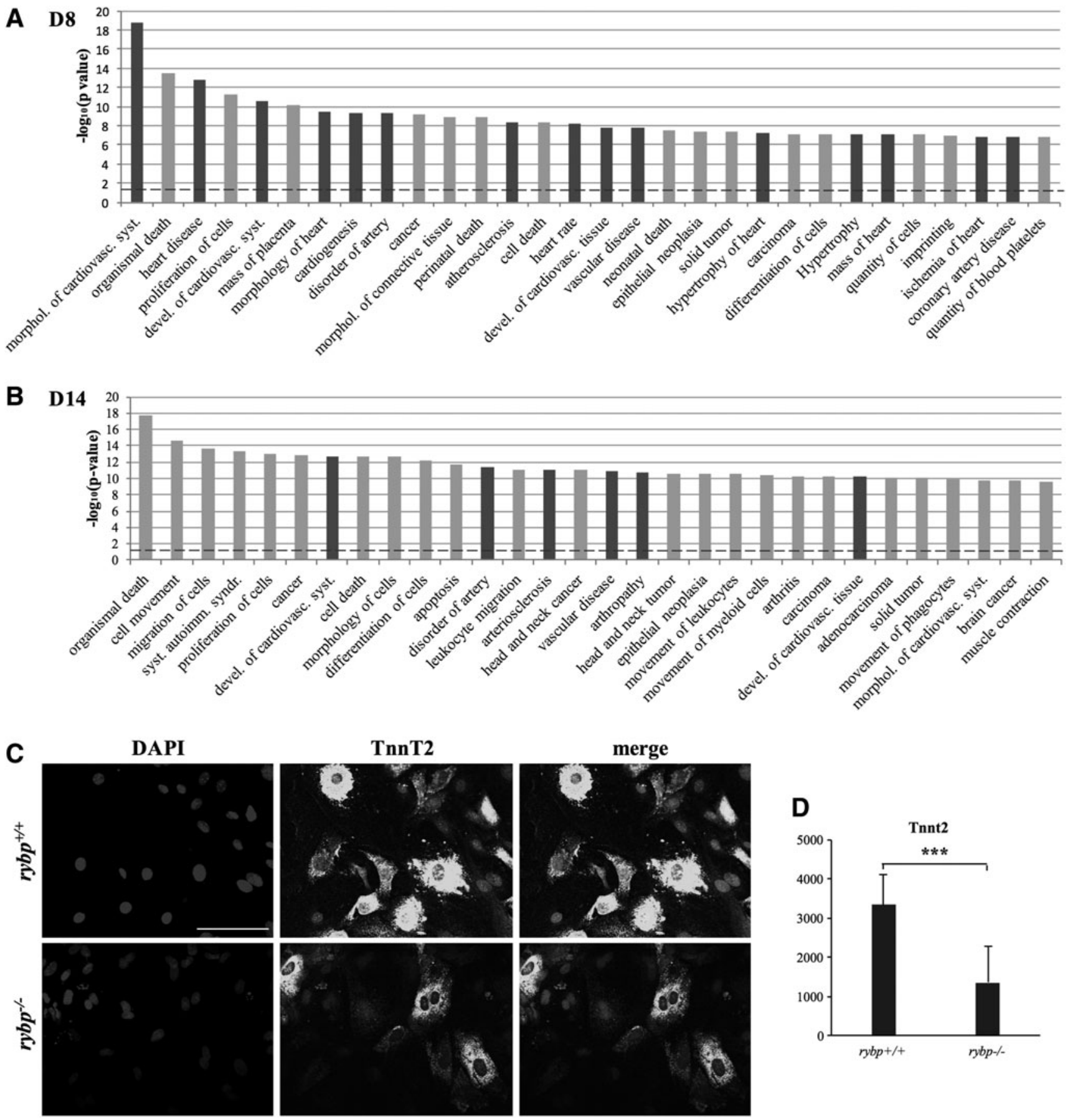

FIG. 4. (A-B) Functional categories overrepresented among genes with significantly different expression in WT and $r y b p^{-1-}$ ESCs. Vertical axis indicates the negative $\log _{10}$ transformed significance value of the enrichment calculated by Fisher's Exact Test. The horizontal (intermitted) line shows the $P=0.05$ threshold generally accepted as the criterion for the selection of significant enrichments. (A): samples from day 8. (B): samples from day 14. (C) Immunocytochemical localization of the cardiac Tnnt 2 protein (light gray) in $r y b p^{+/+}$and $r y b p^{-/-}$CMCs. Immunofluorescence analysis of CMCs derived from wild-type $\left(r y b p^{+/+}\right)$and null mutant $\left(r y b p^{-/-}\right)$ESCs at day 21 of differentiation using an anti-cardiac troponin $\mathrm{T}$ antibody reveals downregulation of cardiac troponinT (Tnnt2) in the mutants. Scale bar: $100 \mu \mathrm{m}$; Objective: $20 \times$. (D) Semi-quantification of Tnnt2 levels of $(\mathbf{C})$ by using Olympus FluoView software. Means are standard deviation \pm SD. Values of $P<0.05$ were accepted as significant $(* * * P<0.001)$. Statistical method: $t$-test type 3.

cardiac differentiation. On the contrary, one of the most upregulated gene during cardiac differentiation was Tbx3 $\left(\mathrm{d} 0: \mathrm{FC}=4.63\right.$, padj $=5.95 \times 10^{-3} ; \mathrm{d} 8: \mathrm{FC}=3.07$, padj $=$ $5.53 \times 10^{-7} ; \mathrm{d} 14: \mathrm{FC}=3.53$, padj $=2.11 \times 10^{-6}$ Supplementary Table S2), which is required for pacemaker and conduction system development in the mammalian heart. Tbx3 was present nearly $5 \times$ higher in the rybp mutants ESCs compared with the WT (d0) and was induced nearly $4 \times$ and $5 \times$ more in CMCs during cardiac differentiation. Six 1, which functions in cardiac progenitor cells but is 
stably silenced on cardiac differentiation, was also underrepresented in the rybp null ESCs (d0) and CMCs (d8; d14) $\left(\mathrm{d} 0: \mathrm{FC}=75.00\right.$, padj $=1.74 \times 10^{-2} ; \mathrm{d} 8: \mathrm{FC}=-5.23$, padj $=$ $5.73 \times 10^{-1} ; \mathrm{d} 14: \mathrm{FC}=-2.45$, padj $=9.48 \times 10^{-1}$ ) [19]. Our DNA-Seq data indicate that key cardiac differentiation pathways are impaired in the rybp null cells. This suggested that altered Rybp dosage led to the improper execution of the cardiac developmental program.

\section{Rybp-deficient ESCs do not express structural genes that are essential for contractility of matured CMSc}

The observation that rybp ${ }^{-/-}$CMCs cannot form rhythmically beating CMCs motivated us to perform gene function enrichment analysis using the IPA knowledge base and to examine the expression level of genes that are important for CMC contractility. IPA analysis revealed that $r y b p^{-1-}$ CMCs have an almost complete lack of organized myofibrils and Z-line genes (eg, Actn1, Myh6, Myh7, Myl2, Myl3, Myl4, Myod, Myom1, Tnni1, Tnni2, Tnni3, Tnnt2) when compared with normal WT CMCs (Supplementary Table S8). Among these genes, Tnnt2 is a key component of the troponin complex in CMCs. It has a regulatory role in $\mathrm{CMC}$ contraction by anchoring troponinI and troponinC to tropomyosin on the thin filaments in the sarcomeres and also confers a $\mathrm{Ca}^{2+}$ dependence on sarcomere contraction. Since the $r y b p^{-/-}$CMCs exhibit deficiency in terminal differentiation marker Tnnt 2 mRNA induction, we analyzed the spatial distribution of the Tnnt 2 protein product as well (Fig. 4C). Immunostaining of late-stage CMCs (d21) confirmed that cardiac Tnnt2 is localized in the cytoplasm and exhibits strong staining in the wild-type $\mathrm{CMCs}$ and its presence is less prominent in the rybp ${ }^{-/-}$cells (Fig. 4C, D). These data demonstrate that the absence of Rybp interferes with the normal expression of structural genes that are important for contractility, and it may have an important role in regulating $\mathrm{CMC}$ contraction and heartbeat.

\section{Rybp-deficient ESCs can be partially rescued by ectopic rybp}

Having shown that lack of rybp led to an impaired differentiation and interferes with CMC contractility, we assessed whether ectopic expression of Rybp might rescue the cardiac phenotype (no rhythmically contracting CMCs, impaired cardiac gene expression profile) of the $r y b p^{-/-}$ cells. We have postulated that by re-introducing rybp with a lentiviral expression vector (rescued cells; $r y b p^{\text {Res }}$ ) we can possibly induce contraction and restore the gene expression profile in the rescued cells (Fig. 2C).

We re-introduced the rybp cDNA in the $r y b p^{-/-}$ESCs by the lentiviral expression system (Fig. 5A). To this purpose, we generated stable ESC clones expressing the HA-tagged $r y b p$ cDNA in $r y b p^{-/-}$ESCs ( $r y b p^{\text {Res }}$ ESC lines) and tested for Rybp expression by immunohistochemistry (Fig. 5D) and western blotting (Fig. 5B). Lower Rybp expression was detected in the rybp ${ }^{\text {Res }}$ lines compared with WT ESCs by western blot analysis. To see whether this lower protein expression was due to the insufficiency of our lentiviral expression system, we performed quantitative RT-PCR analysis of $r y b p$ mRNA in the $r y b p^{\text {Res }}$ lines. We found 1015 times higher expression of $r y b p$ mRNA in the $r y b p^{\text {Res }}$ lines compared with WT ESCs (Fig. 5C).

To determine whether this level of Rypb was functional, both $r y b p^{-1-}$ and two independent rescued ESC lines $\left(r y b p^{\text {Res1 }} ; r y b p^{\text {Res2 }}\right)$ were allowed to differentiate toward CMCs. As the results showed, increased spontaneous beating activity in 20\%-25\% of the rescued CMCs (rybp ${ }^{\text {Res } 1 \text {; }}$ $r y b p^{\text {Res2 }}$ ) was observed (Fig. 5E). Microscopic observations revealed an increased cellularity in the $r y b p^{\text {Res }}$ clones compared with the parental $r y b p^{-/-}$cells (Fig. 5F). Molecular analysis of the gene expression profile confirmed that ectopic Rybp was able to partially rescue the cardiac defect: Is11, Tnnti3, and Myh6 expression was partially restored (Fig. 5G). Furthermore, germ line-specific Tex11, Ddx4, and Piwil2 expression was downregulated in $r y b p^{\text {Res }}$ lines, suggesting that Rybp is a repressor of germ-specific genes and absence of Rybp leads to activation of these promoters. This experiment also showed that a normal dosage of Rybp is required for both activation (some of the cardiac) and repression (germ specific) of target genes.

\section{Discussion}

We have previously shown the correct dose of Rybp required for maintaining the appropriate spatiotemporal expression pattern and levels of Rybp for proper CNS development, thereby providing an in vivo mouse model of NTDs [6]. In this study, we provided evidence for the expression of Rybp during mouse heart development and analyzed the consequences of the loss of rybp on in vitro cardiac differentiation. We found that homozygous rybpdeficient ESCs formed cell clusters but were not able to differentiate into rhythmically beating CMCs in vitro, suggesting the requirement of rybp for proper cardiac differentiation and contractility. Gene expression analysis of undifferentiated ESCs and CMCs during cardiac differentiation

FIG. 5. Reconstitution of Rybp expression and function in $r y b p^{-1-}$ ESCs. (A) Lentiviral construct used for ectopic expression of Rybp. (B) Western blot analysis of WT, rybp ${ }^{-1-}$, and two independent rescued ESC lines $\left(r y b p^{\text {Resl }}\right.$; rybp ${ }^{\text {Res2 } 2}$ ). Western blot was probed with anti-Dedaf antibody $(38 \mathrm{kDa})$. (C) Quantitative RT-PCR analysis of $r y b p^{\text {Res }}$ clones compared with WT cells. (D) Immunostaining of WT, rybp ${ }^{-}$, and rybp Res ESC clones for Rybp expression. ESCs were fixed and immunostained with anti-Dedaf antibody. (E) Spontaneous beating activity of differentiated WT, $r y b p^{-1-}$, and rescued ESC lines $\left(r y b p^{\text {Res } 1} ; r y b p^{\text {Res2 }}\right)$. Beating of differentiated EBs was counted at day 0, 8, and 11 of differentiation. (F) Microscopic analysis of cellularity of differentiated WT, rybp ${ }^{-1-}$, and rescued ESC lines (rybp ${ }^{\text {Res1 }}$; rybp ${ }^{\text {Res2 }}$ ). (G) Quantitative RT-PCR analysis of cardiac- and germ cell-specific differentiation markers. RNA was extracted, reverse transcribed from differentiated cardiac cells generated from WT, rybp $p^{-1-}$, and rescued ESC lines $\left(r y b p^{\text {ResI }} ; r^{2 y b p^{R e s 2}}\right)$ at day $0,4,8$, and 14 of differentiation, and analyzed for expression of differentiation markers Is11, Tnni3, Myh6, Tex11, Ddx4, and Piwil2. Gapdh transcripts were amplified as an internal control. Values and means: \pm SD $* P<0.05 ; * * P<0.01 ; * * * P<0.001$; $* * * * P<0.0001 ;(n=5)$ Statistical method: $t$-test type 3 . EBs, embryoid bodies. 
demonstrated upregulation (Tbx3) and downregulation of several transcription factors (Is11, Plagl1) and structural myofibril proteins (Actn1, Myh6, Myh7, Myl2, Myl3, Myl4, Myocd, Myom1, Tnni1, Tnni2, Tnni3, Tnnt2) that are critical for heart development.

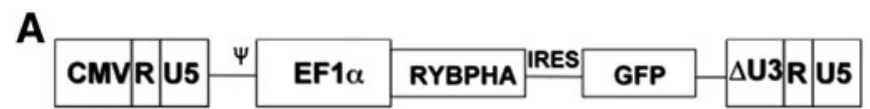

B

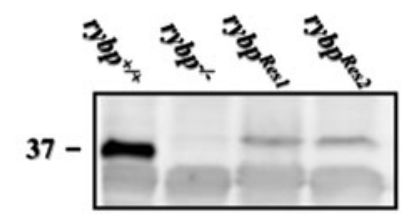

C
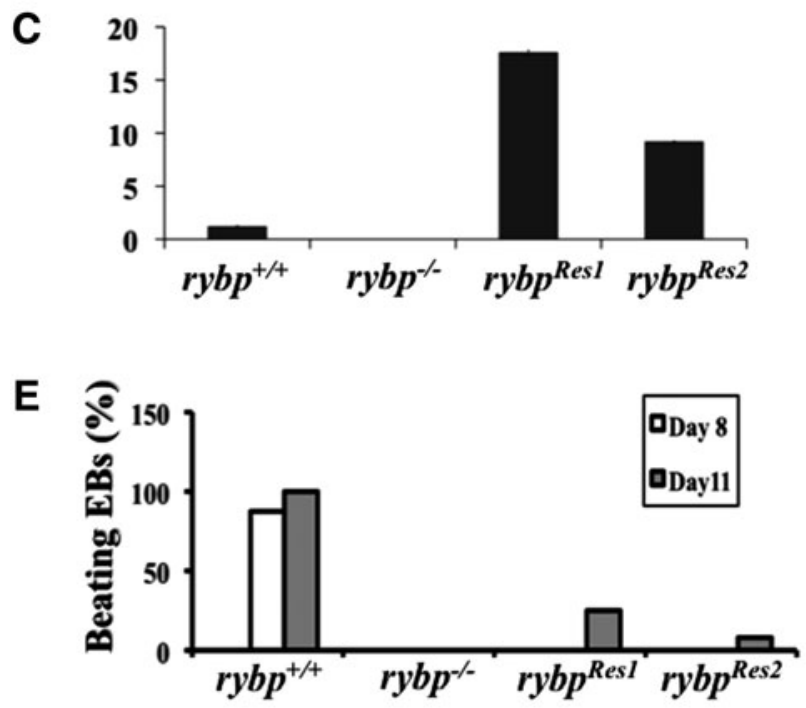

Aiming at finding the causatives of the observed phenotype, we have analyzed whether an alteration in pluripotency, or key developmental and cardiac gene expression is responsible for the impairment. One possible explanation for the impaired cardiac differentiation of the mutants is that
D
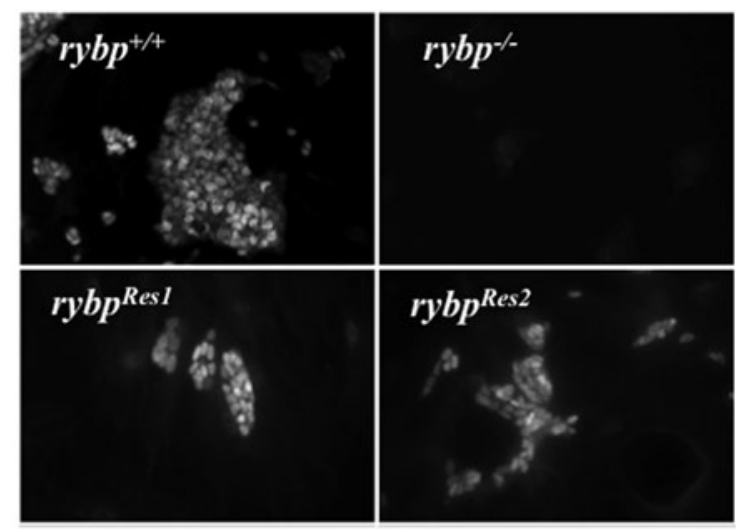

$\mathbf{F}$

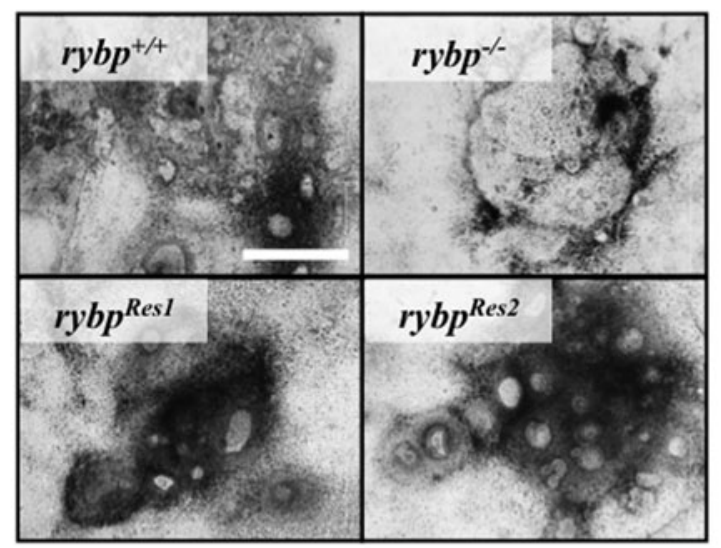

\section{G}
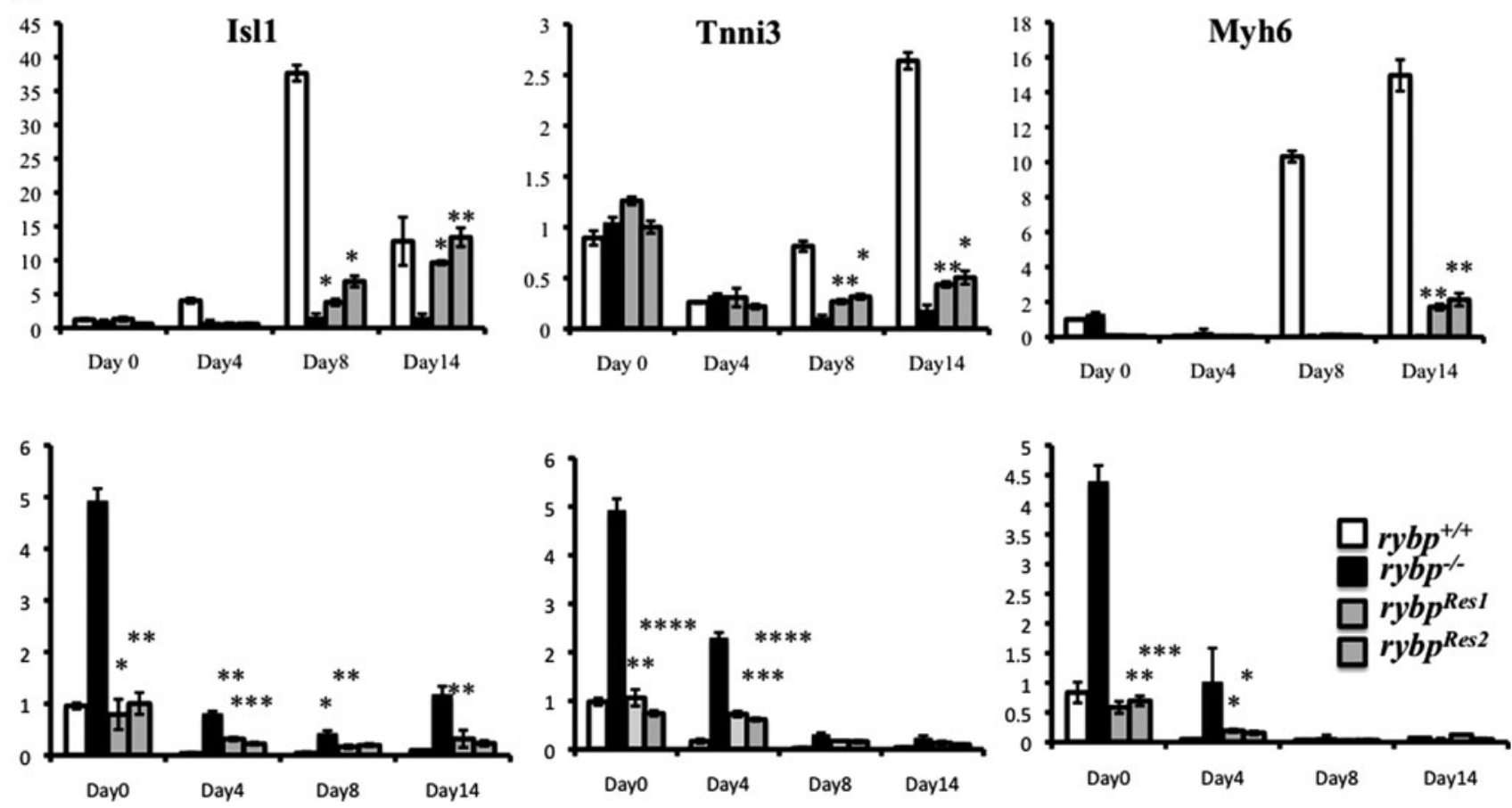
pluripotency gene silencing is incomplete during differentiation, which may cause impaired differentiation. First, we analyzed the key pluripotency gene (eg, Rex1, Oct4, Nanog) expression levels and we concluded that there were no significant changes in the kinetics of pluripotency gene expression between the two cell populations ( $r y b p^{-/-}$vs. $\left.r y b p^{+/+}\right)$. We concluded that proper silencing of pluripotency genes shows the expected kinetics, thus it cannot be the causative of the observed differentiation defect.

Second, since the mammalian heart essentially has a mesodermal origin, we have tested whether the mesoderm is properly formed in the rybp mutant cells. We did not find a difference in the expression pattern of the pan-mesodermal marker Bra/T, which, as expected, was nearly absent in the undifferentiated ESCs and transiently expressed during EB formation peaking at $\mathrm{d} 4$. Gsc, which is another marker or early mesodermal lineage commitment, exhibited normal expression pattern in the rybp mutants as well. Notably, the level of Gsc transcripts was 3-fold higher in the undifferentiated $r y b p^{-/-}$than in the wild-type ESCs, suggesting that an abundant pool of mesodermal precursors is available in the $r y b p^{-/-}$cells at the beginning of cardiac differentiation. Taken together, these data showed that silencing of pluripotency gene expression and formation of mesoderm were comparable in both the WT and the rybp null mutant cells and that the defect in cardiac differentiation is probably due to later-stage causatives. By examining the induction kinetic of several key cardiac transcription factors, we have found that induction of Isl1 expression was defective in the rybp $^{-/-}$cells $(10 \times$ vs. $2 \times$ by d $8 ; 12 \times$ vs. $5 \times$ by d10) (Fig. $3)$. Isl1 is an essential regulator of cardiac progenitor differentiation and also an important transcriptional factor for the development of the secondary heart field. Thus, one possible explanation for the phenotype is that deficiency in Isl1 expression leads to improper cardiac progenitor cell differentiation and these resulted in defects in producing functional CMCs in the $r y b p^{-/-}$mutants. It is also worthwhile to note that Isl1 belongs to the family of homeodomain transcriptional regulators, thus it can be a potential target of Rybp by a PcG-dependent fashion. PcG proteins regulate homeotic gene expression and are essential for organ development. It had been previously shown that members of the PRC1 and PRC2 complexes have essential roles in early embryonic development; however, few of their target genes are known in mammals $[20,21]$. Some of the PcG proteins were also shown to have an essential function in mammalian heart development. A key cardiac regulatory gene, six 1 , which also has altered expression in the $r y b p^{-\gamma}$ CMCs, is suppressed by a PcGmediated mechanism by PRC2 member Ezh2 and Eed in cardiac differentiation [22]. Loss of Ezh2 in cardiac progenitors and in CMCs mediated by early myocardial transcription factor $\mathrm{Nkx} 2.5^{\mathrm{Cre}}$ resulted in lethal heart abnormalities and disrupted CMC gene expression. PRC1 member Rae28 knockout mice displayed cardiac anomalies similar to congenital heart diseases in humans [23]. Rae28 sustains Nkx2.5 expression in CMCs and plays a key role in cardiac lineage commitment [24]. Furthermore, in ES cell-based assays, the loss of function of the Rybp binding partner Yy1 resulted in a decrease in CMCs, whereas Yy1 gain of function enhanced the generation of cardiac cells [25]. As far as the potential role of Rybp in PRC-mediated repression is concerned, we still do not have a clear understanding of how Rybp functions as a PRC member or how PcG complexes containing Rybp reach their targets. Rybp is generally considered a PcG protein and a transcriptional repressor [5,26], so downregulation of downstream targets that results from the absence of rybp seems paradoxical. This leads to two alternate possibilities. Either Rybp normally represses factors that would otherwise repress the target genes (absence of a putative repressor results in the downregulation of downstream targets), or Rybp functions as a transcriptional activator on some genes. In the first case, we would expect that the repressive function of Rybp is typical of a PRC1 complex-dependent regulation. In the second case, activation by Rybp would most likely be independent of PcG proteins although it is also possible that Rybp specifically displaces PRC1 from chromatin and facilitates transcriptional activation in this manner [27]. By the biochemical characterization of Rybp Containing Multimeric Protein Complexes, much of which should also contain Ring1 or Yyl proteins, this paradox might be easier to solve.

On the other hand, lack of Rybp did not result in a significant change in the expression level of some other homeodomain transcription factors. The level of Tbx5, which is an essential gene of mammalian heart development, did not change in our experiments, suggesting that Rybp regulates cardiac transcription factors via different regulatory circuits. It has also been reported that Rybp is functioning as member of the noncanonical PRC1 complex in a broad variety of target genes [4]. Rybp, as a member of the noncanonical PRC, has an emerging and complex role in the regulation of gene expression, differentiation, and development. Furthermore, Rybp defines functionally different PRC1 family complexes, thus preventing the incorporation of other canonical PRC1 subunits, such as $\mathrm{Cbx}, \mathrm{Scm}$, and Phc. The precise biological functions of these versatile complexes are not known [4]. To clarify whether Rybp is functioning as a member of the PRC1 complexes during heart development certainly needs further investigations. Notably, transcriptome analysis did not show any disturbance in PcG protein distribution between the undifferentiated $r y b p^{-1-}$ and WT ESCs or CMCs (Supplementary Tables S2 and S3). This suggests that the lack of functional Rybp had no significant effect on the expression of the PRC1 and PRC2 members.

Downregulation of terminal cardiac marker Tnnt 2 in the $r y b p^{-1-}$ CMCs may indicate the role of Rybp in regulating structural proteins of the functional sarcomer. Lack of Tnnt2 in mouse models caused early embryonic lethality due to a lack of heartbeats [28]. Our gene expression analysis showed decreased expression of Tnnt 2 in the rybp null mutants $(\sim 2,000 \times$ vs. $500 \times$ by d8; $3,000 \times$ vs. $500 \times$ by d 10 and $3,500 \times$ vs. $500 \times$ by d14); however, it was still abundantly expressed even in the rybp ${ }^{-1-}$ mutant CMCs $(500 \times)$ compared with the WT CMCs (Fig. 3). This suggests that perhaps not only the availability but also the functionality of Tnnt2 is critical for the contraction of the WT CMCs. Members of PRC2 are also required later in heart development, as demonstrated by the conditional TNT-Cre inactivated Eed knockout mice. However, Ezh2 inactivation (another essential member of PRC2) by TNT-Cre did not cause an overt phenotype, likely because of functional 
redundancy with Ezh1 [22]. Further experiments need to clarify whether the assembly of functional sarcomeres is impaired in the rybp mutants.

Our recent study also showed that the defect in contractility in the rybp null CMCs could not be restored by adding ASC to the culture as a supplement. ASC has multiple effects on cell proliferation and differentiation, especially of promoting mesenchymal cells toward adipogenesis, osteogenesis, chondrogenesis, and myogenesis. ASC is also able to restore the contractile response in patients after heart failure or myocardial infarction [29]. However, in our experiments, ASC was not able to restore contractility of the mutant CMCs but increased the cell mass of the $r y b p^{-/-}$and $r y b p^{+/+}$CMCs. Little is known about the exact effect of ASC, but it has been reported that reactive oxygen species (ROS) regulate the intracellular signal transduction of the $\beta$ adrenergic pathway, that is, its receptors, G-proteins and adenylyl cyclase, function in the myocardium [30]. These observations have led to the hypothesis that ROS directly affect myocardial contractile function through alteration of the $\beta$-adrenergic pathway. Future experiments need to clarify whether members of the $\beta$-adrenergic pathway are defective in the rybp ${ }^{-1-}$ CMCs.

Importantly, re-introduction of rybp by a lentiviral expression vector in rybp deficient ESCs was able to rescue the mutant phenotype and has partially restored contractility of the $r y b p^{-/-}$CMCs. The appearance of contracting cells was paralleled by the expression of early (Isl1) and late (Tnni3) cardiac gene markers, thus suggesting their identity as CMCs.

It is also important to mention that the absence of functional Rybp had a significant effect on the cascade members of germ cell development. This is in agreement with the abundant expression of Rybp in the reproductive systems and the recent observation of Hisada et al., that Rybp functions as a de-repressor of germ specific genes in pluripotent ESCs [31]. Our transcriptome analysis revealed that abundant expression of germ line-specific genes persists during the entire course of in vitro cardiac differentiation and their downregulation is impaired. Our experiments demonstrated that abundant germ line-specific gene expression persists during the entire time course of cardiac differentiation in the mutants. Therefore, we cannot rule out the possible effect of this abundant germ-specific gene expression on the inhibition of normal somatic differentiation (eg, cardiac), which needs further investigation. Especially, recent evidence indicates that germ line-specific genes [eg, vasa (Ddx4), stella (Dppa3)] also function in other cell types, distinct from the germ line or in facilitating differentiation toward endodermal lineage commitment [32,33]. Both genes, Ddx4 and Dppa3, are aberrantly upregulated in our rybp-deficient ESCs and Ddx4 is expressed throughout cardiac-derived differentiation in $r y b p^{-/-}$CMCs. In our experiments, forced expression of exogenous Rybp partially restored the repressed state of genes that is important for normal germ cell development in the rybp-deficient ESCs. This underlines the function of Rybp in epigenetic regulation at early-stage embryonic development [31] and pinpoints the importance of germ line gene silencing during somatic differentiation.

In summary, we demonstrate, for the first time, that the differentiation capacity of ESCs that lack rybp toward the cardiogenic cell fate is severely impaired. We find that $r y b p$ null ESCs are blocked in cardiac differentiation. Finally, we present evidence that Rybp contributes to the contractility of CMCs during stem cell differentiation.

\section{Acknowledgments}

The authors thank Dr. Joseph Locker for stimulating discussions. They are indebted to Radone Gyugyi for the superb technical assistance rendered.

This work was supported by NKTH-OTKA FP7 “Mobility" HUMAN-MB08C-80205; InduStem, PIAP-GA-2008230675; InduHeart, PEOPLE-IRG-2008-234390; InduVir, PEOPLE-IRG-373 2009-245808; and Plurisys HEALTH2007-B-223485 and Research Center of Excellence 9878/ 2015/FEKUT.

\section{Author Disclosure Statement}

No competing financial interests exist.

\section{References}

1. Davidson EH, JP Rast, P Oliveri, A Ransick, C Calestani, et al. (2002). A genomic regulatory network for development. Science 295:1669-1678.

2. Novershtern N, A Subramanian, LN Lawton, RH Mak, WN Haining, et al. (2011). Densely interconnected transcriptional circuits control cell states in human hematopoiesis. Cell 144:296-309.

3. Odom DT, N Zizlsperger, DB Gordon, GW Bell, NJ Rinaldi, et al. (2004). Control of pancreas and liver gene expression by HNF transcription factors. Science 303:1378-1381.

4. Gao Z, J Zhang, R Bonasio, F Strino, A Sawai, et al. (2012). PCGF homologs, CBX proteins, and RYBP define functionally distinct PRC1 family complexes. Mol Cell 45:344-356.

5. Garcia E, C Marcos-Gutierrez, M del Mar Lorente, JC Moreno and M Vidal. (1999). RYBP, a new repressor protein that interacts with components of the mammalian Polycomb complex, and with the transcription factor YY1. EMBO J 18:3404-3418.

6. Pirity MK, J Locker and N Schreiber-Agus. (2005). Rybp/ DEDAF is required for early postimplantation and for central nervous system development. Mol Cell Biol 25: 7193-7202.

7. Pirity MK, WL Wang, LV Wolf, ER Tamm, N SchreiberAgus, et al. (2007). Rybp, a polycomb complex-associated protein, is required for mouse eye development. BMC Dev Biol 7:39.

8. Nagy A, J Rossant, R Nagy, W Abramow-Newerly and JC Roder. (1993). Derivation of completely cell culture-derived mice from early-passage embryonic stem cells. Proc Natl Acad Sci U S A 90:8424-8428.

9. Magin TM, J McWhir and DW Melton. (1992). A new mouse embryonic stem cell line with good germ line contribution and gene targeting frequency. Nucleic Acids Res 20:3795-3796.

10. Lois C, EJ Hong, S Pease, EJ Brown and D Baltimore. (2002). Germline transmission and tissue-specific expression of transgenes delivered by lentiviral vectors. Science 295:868-872.

11. Dull T, R Zufferey, M Kelly, RJ Mandel, M Nguyen, et al. (1998). A third-generation lentivirus vector with a conditional packaging system. J Virol 72:8463-8471. 
12. Klincumhom N, MK Pirity, S Berzsenyi, O Ujhelly, S Muenthaisong, et al. (2012). Generation of neuronal progenitor cells and neurons from mouse sleeping beauty transposon-generated induced pluripotent stem cells. Cell Reprogram 14:390-397.

13. Rungarunlert $\mathrm{S}, \mathrm{N}$ Klincumhom, I Bock, C Nemes, $\mathrm{M}$ Techakumphu, et al. (2011). Enhanced cardiac differentiation of mouse embryonic stem cells by use of the slowturning, lateral vessel (STLV) bioreactor. Biotechnol Lett 33:1565-1573.

14. Rungarunlert S, N Klincumhom, T Tharasanit, M Techakumphu, MK Pirity, et al. (2013). Slow turning lateral vessel bioreactor improves embryoid body formation and cardiogenic differentiation of mouse embryonic stem cells. Cell Reprogram 15:443-458.

15. Trapnell C, L Pachter and SL Salzberg. (2009). TopHat: discovering splice junctions with RNA-Seq. Bioinformatics 25:1105-1111.

16. Morey L, G Pascual, L Cozzuto, G Roma, A Wutz, et al. (2012). Nonoverlapping functions of the Polycomb group Cbx family of proteins in embryonic stem cells. Cell Stem Cell 10:47-62.

17. Zheng L, O Schickling, ME Peter and MJ Lenardo. (2001). The death effector domain-associated factor plays distinct regulatory roles in the nucleus and cytoplasm. J Biol Chem 276:31945-31952.

18. Stanton SE, JK Blanck, J Locker and N Schreiber-Agus. (2007). Rybp interacts with Hippi and enhances Hippimediated apoptosis. Apoptosis 12:2197-2206.

19. Delgado-Olguin P, Y Huang, X Li, D Christodoulou, CE Seidman, et al. (2012). Epigenetic repression of cardiac progenitor gene expression by Ezh2 is required for postnatal cardiac homeostasis. Nat Genet 44:343-347.

20. Boyer LA, K Plath, J Zeitlinger, T Brambrink, LA Medeiros, et al. (2006). Polycomb complexes repress developmental regulators in murine embryonic stem cells. Nature 441:349-353.

21. Simon JA and RE Kingston. (2009). Mechanisms of polycomb gene silencing: knowns and unknowns. Nat Rev Mol Cell Biol 10:697-708.

22. He A, Q Ma, J Cao, A von Gise, P Zhou, et al. (2012). Polycomb repressive complex 2 regulates normal development of the mouse heart. Circ Res 110:406-415.

23. Takihara Y, D Tomotsune, M Shirai, Y Katoh-Fukui, K Nishii, et al. (1997). Targeted disruption of the mouse homologue of the Drosophila polyhomeotic gene leads to altered anteroposterior patterning and neural crest defects. Development 124:3673-3682.

24. Shirai M, T Osugi, H Koga, Y Kaji, E Takimoto, et al. (2002). The Polycomb-group gene Rae28 sustains Nkx2.5/ Csx expression and is essential for cardiac morphogenesis. J Clin Invest 110:177-184.
25. Gregoire S, R Karra, D Passer, MA Deutsch, M Krane, et al. (2013). Essential and unexpected role of Yin Yang 1 to promote mesodermal cardiac differentiation. Circ Res 112:900-910.

26. Tavares L, E Dimitrova, D Oxley, J Webster, R Poot, et al. (2012). RYBP-PRC1 complexes mediate H2A ubiquitylation at polycomb target sites independently of PRC2 and H3K27me3. Cell 148:664-678.

27. Richly H, L Rocha-Viegas, JD Ribeiro, S Demajo, G Gundem, et al. (2010). Transcriptional activation of polycombrepressed genes by ZRF1. Nature 468:1124-1128.

28. Nishii K, S Morimoto, R Minakami, Y Miyano, K Hashizume, et al. (2008). Targeted disruption of the cardiac troponin $\mathrm{T}$ gene causes sarcomere disassembly and defects in heartbeat within the early mouse embryo. Dev Biol 322: 65-73.

29. Shinke T, J Shite, H Takaoka, K Hata, N Inoue, et al. (2007). Vitamin C restores the contractile response to dobutamine and improves myocardial efficiency in patients with heart failure after anterior myocardial infarction. Am Heart J 154:645.

30. Choi KM, YK Seo, HH Yoon, KY Song, SY Kwon, et al. (2008). Effect of ascorbic acid on bone marrow-derived mesenchymal stem cell proliferation and differentiation. J Biosci Bioeng 105:586-594.

31. Hisada K, C Sanchez, TA Endo, M Endoh, M RomanTrufero, et al. (2012). RYBP represses endogenous retroviruses and preimplantation- and germ line-specific genes in mouse embryonic stem cells. Mol Cell Biol 32:1139_ 1149.

32. Gustafson EA and GM Wessel. (2010). Vasa genes: emerging roles in the germ line and in multipotent cells. Bioessays 32:626-637.

33. Wongtrakoongate P, M Jones, PJ Gokhale and PW Andrews. (2013). STELLA facilitates differentiation of germ cell and endodermal lineages of human embryonic stem cells. PLoS One 8:e56893.

Address correspondence to:
Dr. Melinda Katalin Pirity
Institute of Genetics
Biological Research Centre
Hungarian Academy of Sciences
Szeged H-6726
Hungary

E-mail: pirity.melinda@brc.mta.hu

Received for publication December 8, 2014 Accepted after revision May 22, 2015

Prepublished on Liebert Instant Online June 3, 2015 